\section{Okolo AA \\ Okonkwo RI Ideh RC}

DOI:http://dx.doi.org/10.4314/njp.v43i4.5

Accepted: 8th August 2016

Okolo AA ( $\boldsymbol{\nabla}$ )

Okonkwo RI, Ideh RC

Neonatal Unit,

University of Benin Teaching Hospital PMB 1111

Benin City, Edo State, Nigeria.

Email: angelneneo@yahoo.com

\title{
Spectrum of neonatal diseases requiring respiratory support in UBTH, Benin City, Edo State, Nigeria
}

\begin{abstract}
Introduction: In Nigeria, eighty two percent of the three leading causes of neonatal mortality may require respiratory support for their management, yet this is unavailable.

Objective: To review the spectrum of respiratory disorders that were ventilated, their outcomes and the contribution of such support to survival

Methods: A data base of cases managed in the unit is maintained and reviewed regularly for enhancement of quality of care. Such prospectively documented information on babies who received respiratory support over the period $1^{\text {st }}$ January to $31^{\text {st } J u n e ~}$ 2014 were analysed.

Results: Five hundred and seventy six babies were admitted. Fortynine $(8,5 \%)$ received ventilator support. These comprised preterm (77.6\%) and term (22.4\%) babies with mean gestational age of 33.2 weeks (range 28-41). The spectrum of disorders supported were: respiratory distress syndrome (RDS) $55.1 \%$, asphyxia $20.4 \%$, sepsis $12.3 \%$, acute bilirubin en-
\end{abstract}

cephalopathy (ABE) 8.2\%, transient tachypnoea of the new-born (TTNB) $2 \%$ and neonatal tetanus (NT) $2 \%$.

They were non- invasive support (NIVRS) 33(67.3\%) for respiratory distress; invasive support (IVRS) $16(32.7 \%$ ) for respiratory failure. NIVRS was mostly for RDS (88.9\%); ABE (100\%) received invasive support. Mortality was: NIVRS7/33(21.2\%); IVRS 11/16(68.75\%). Respiratory dysfunction contributed $25.4 \%$ of the total neonatal mortality of 123 per thousand. Survival was $63.3 \%$. Conclusion: The morbidities were: asphyxia, prematurity, sepsis, $\mathrm{ABE}$, and tetanus. Ventilator support was non-invasive with bubble CPAP and invasive with mechanical ventilation through endotracheal intubation. Survival was improved. There is the urgent need to commence and sustain basic non -invasive respiratory support in all neonatal units in Nigeria.

Key Words: Spectrum; Neonatal diseases; Respiratory support

\section{Introduction}

Close monitoring of a mother in labour with prompt intra partum care and provision of delivery room resuscitation have all been shown to reduce asphyxia rates. ${ }^{1}$ The changing pattern of admissions with increase in preterm births over the more recent times indicate the need to search for newer approaches to address problems associated with prematurity and LBW. It is well known fact that prematurity is often complicated by respiratory problems.

We realise that establishing and maintaining an ICU/ ventilator facilities is expensive even in the developed countries. However, their use in such developed economies contributed significantly to neonatal survival. ${ }^{1,2}$

Respiratory support though not curative is essential for management of neonatal respiratory problems when function is inadequate. Such support could be invasive (via endotracheal tube) or non-invasive (NIV), for short or long periods. ${ }^{3}$

Respiratory dysfunction is a major component of the causes of neonatal mortality. Presently in Nigeria, neonatal mortality rates are unacceptably high. Eighty two percent of the causes of these deaths are largely preventable. The major causes of neonatal deaths are asphyxia, prematurity, infection and tetanus. ${ }^{4}$ Globally, three of these are also responsible for $75 \%$ of the causes of newborn deaths. ${ }^{5}$ Developed countries have made significant advances and reduced neonatal mortality because they focused on management modalities that target these causes in their approach towards reduction. Progress is particularly slow in Africa. Nigeria ranks second and contributes $9 \%$ of the global mortality figures. ${ }^{5}$ Artificial ventilation for new-borns was introduced in 
1959. Despite the fact that its use at the time was controversial for RDS because the ventilators were not designed specifically for new-borns and in particular for preterm newborns. ${ }^{6}$ Its use contributed to decreased rates of mortality in larger infants who died of inadequate respiratory effort. ${ }^{7}$

The neonatal mortality rate (NMR) in the United States has decreased markedly over the past 60 years. In 1935 , before the field of neonatology existed, the NMR was 35 per 1000 live births. ${ }^{8}$ Since the 1950 s, medical advances have decreased the NMR in a linear fashion to its current rate of 4 per 1000 live births. ${ }^{9,10}$ Despite the improvements in neonatal care in high-income settings, neonatal mortality contributes $40 \%$ to the mortality rate for children younger than 5 years globally. ${ }^{8}$ This emphasises the need to refocus neonatal care in resource limited settings where the gap in standards and quality exist.

Mechanical ventilation was not widespread outside of Europe and USA until the 1980s. ${ }^{11}$ It came into use in India in the late 1980s and showed some improvements to mortality indicators. ${ }^{12}$ By 1995 it was increasingly utilised and infants with RDS accounted for $36 \%$ of its use across the neonatal units in India. ${ }^{13}$ Nevertheless in that setting, another study revealed that $17.8 \%$ of newborns who required ventilator care could not be referred because of financial constraints. ${ }^{14}$ Limited financial access is still a major constraint to neonatal care for most of the resource limited economy countries. Thus, the level of technology available to treat a new-born with respiratory distress varies significantly according to where the infant is born, the distance the sick infant has to travel to reach a health centre with the appropriate level of care, and financial resources of the family. Despite the increased use of more sophisticated technology, morbidity and mortality rates related to RDS remain high in India ${ }^{15}$ largely because of disparities in standards and limited access to quality care. Similar challenges are experienced in Neonatal care in low resource settings like in Nigeria where the use of ventilator support is yet to become widespread. ${ }^{16}$ To experience remarkable improvements in neonatal survival these technological advancements are required. In the introduction of these advanced technological skills, it is to be realised that ventilator care cannot be used as a standalone support. Its use requires other ancillary support. ${ }^{1}$ This was noted in the work of Bhutta $e t$ al in a study of risk factors for mortality in infants with RDS at Aga Khan University Hospital in Pakistan. Bhutta and Yusuf noted that despite access to high technology, the medical staff required requisite training for the appropriate care of sick new-borns. ${ }^{15}$ Basic neonatal care support like provision of warmth, gavage feeding or more sophisticated parenteral alimentation and monitoring of functions should be available in the context of neonatal intensive care to support the technological efforts like ventilator support. This is not yet so in Nigeria where the population has limited access to acceptable standard of care. There are wide gaps and variation in the level of care available to the new-borns in Nigeria. ${ }^{16}$
In the developed countries, the refinement of mechanical ventilation dramatically improved the survival of many high-risk neonates. ${ }^{17}$ Respiratory distress accompanies a myriad of problems in the newborn and thus constitutes a major clinical sign for hospital admissions into neonatal units. ${ }^{18}$ Respiratory support is therefore urgently needed when respiratory function is inadequate to avoid further deterioration and death.

Prematurity contributes significantly to cases of respiratory distress and emphasises the need for availability of respiratory support. It is therefore not surprising that premature births account for $35 \%$ of neonatal deaths globally. 5,18

Respiratory support had been in place for the care of sick new-born in our establishment in the 1980s but the technology was not sustained through the 1990s and beyond for various reasons common to resource poor settings. It has only been recently reintroduced in late 2013. ${ }^{1}$ Because of differences in epidemiology of diseases, the spectrum of disorders needing respiratory support in our local environment may differ from that of developed communities. Therefore, we conducted a review of our recently introduced strategy to better understand the spectrum of disorders requiring respiratory support, the type of interventions provided, whether these have decreased mortality attributable to respiratory dysfunction in our low resource setting. Results of this finding may be useful for policy setting for improved quality and standard of new-born care services nationally.

This survey aimed at the documentation of evidence for the contribution of ventilator support in the management of respiratory dysfunction to survival and thus the urgent need for its introduction in neonatal care in Nigeria.

\section{Subjects and Methods \\ Study site}

This study was conducted at the special care baby unit of our teaching hospital (SCBU). This Neonatal unit (separated into IN Born and Out Born) has a cot capacity of 50. The University of Benin Teaching Hospital neonatal unit (SCBU) is functionally divided into neonatal intensive care, high dependency unit, special care baby unit and transitional care bays. The neonatal unit is equipped with five (5) Neonatal mechanical ventilators, three (3) patented standalone Nasal Continuous Positive Airway Pressure (nCPAP) machines and capacity to offer improvised CPAP using our local devices.

\section{Methods and Procedure}

The study was conducted from $1^{\text {st } J a n u a r y ~ t o ~} 31^{\text {st } J u n e}$ 2014. It was a prospective descriptive study of all cases with respiratory dysfunction identified from the unit's data base. Data obtained included: Babies' gestational age, gender, mode of delivery, birth weight category, respiratory features, diagnosis, indication, mode and 
duration of respiratory support and outcome. The subjects consisted of all babies who received respiratory support.

The Silverman-Anderson score was used to grade the severity of respiratory distress and to indicate respiratory failure. ${ }^{19}$ The higher score is indicative of more severe degree of respiratory distress. A score greater than 7 indicates that the baby is in respiratory failure. The indication for commencement of respiratory support was according to the Neonatal unit protocol. (Babies with respiratory distress or evidence of increased work done for breathing were commenced on nCPAP). Babies were on non-invasive (NIVRS) when on nCPAP or invasive (IVRS) when on Mechanical ventilation with endotracheal intubation.

\section{Data analysis}

The IBM/SPSS 19 was utilized. The means, ranges, frequencies and percentage were calculated. The indication and mode of support were cross-tabulated with the general characteristics. Chi-square was used to test associations between indication and mode of support with gestational maturity. The level of significance was set at $\mathrm{p}<0.05$ and confidence level at $95 \%$.

\section{Results}

Forty nine $(8.5 \%)$ out of 576 babies admitted during the study period received respiratory support. Table 1 shows the general characteristics of these babies. Gestational age (GA) ranged from 28-41weeks; with a mean of 33.2 \pm 3.69 .

\begin{tabular}{|c|c|c|c|}
\hline \multicolumn{4}{|c|}{ Table 1: General characteristics of the study population } \\
\hline Features & & Characteristic & $\mathrm{n}(\%)$ \\
\hline \multirow[t]{2}{*}{ Gender } & Male & $25(51)$ & $\mathrm{M}: \mathrm{F}=1: 0.96$ \\
\hline & female & $24(49)$ & \\
\hline \multirow[t]{2}{*}{ Booking status } & Booked & $31(63.3)$ & \\
\hline & Unbooked & $18(36.7)$ & \\
\hline \multirow[t]{3}{*}{ Mode of delivery } & SVD & $22(44.9)$ & \\
\hline & ELCS & $4(8.2)$ & \\
\hline & EMCS & $23(46.9)$ & \\
\hline \multirow[t]{2}{*}{ Maturity } & Term & $11(22.4)$ & \\
\hline & Preterm & $38(77.6)$ & \\
\hline \multirow[t]{4}{*}{ Weight Category } & NBW & $15(30.6)$ & \\
\hline & LBW & $12(24.5)$ & \\
\hline & VLBW & $18(36.7)$ & \\
\hline & ELBW & $4(8.2)$ & \\
\hline
\end{tabular}

The spectrum of disorders that received respiratory support were: respiratory distress syndrome (RDS), asphyxia, sepsis, neonatal tetanus and acute bilirubin encephalopathy (Table 2)
Table 2: Diagnosis and indication for support with the mode of support

\begin{tabular}{|c|c|c|c|c|c|}
\hline \multirow{2}{*}{$\begin{array}{l}\text { Diag- } \\
\text { nosis }\end{array}$} & \multirow[t]{2}{*}{$\mathrm{N}(\%)$} & \multirow{2}{*}{$\begin{array}{l}\text { Indication } \\
\text { Distress }\end{array}$} & \multirow{2}{*}{$\begin{array}{l}\mathrm{n}(\%) \\
\text { Failure }\end{array}$} & \multicolumn{2}{|c|}{ Mode of Support n (\%) } \\
\hline & & & & NIV & Invasive \\
\hline RDS & $27(55.1)$ & $25(92.6$ & $2(7.4)$ & $24(88.9)$ & $3(11.1)$ \\
\hline $\begin{array}{l}\text { As- } \\
\text { phyxia }\end{array}$ & $10(20.4)$ & $6(60)$ & $4(40)$ & $5(50)$ & $5(50)$ \\
\hline Sepsis & $6(12.3)$ & $4(66.7)$ & $2(33.3)$ & $3(50)$ & $3(50)$ \\
\hline $\mathrm{ABE}$ & $4(8.7)$ & - & $4(100)$ & - & $4(100)$ \\
\hline TTNB & $1(2)$ & $1(100)$ & - & $1(100)$ & - \\
\hline NNT & $1(2)$ & - & $1(100)$ & - & $1(100)$ \\
\hline Total & $49(100)$ & $36(73.5)$ & $13(26.5)$ & $33(67.3)$ & $16(32.7)$ \\
\hline
\end{tabular}

Respiratory distress syndrome (RDS) $(72.7 \%)$ is significantly associated with the use of non-invasive support while Acute Bilirubin Encephalopathy (ABE) (31.3\%) is significantly associated with invasive support $(\mathrm{p}=0.001)$. Respiratory distress syndrome is the commonest indication for non-invasive support and non-invasive support was the most frequently used mode.

Whilst respiratory distress $36(73.5 \%)$ and respiratory failure $13(26.5 \%)$ were the commonest cause for respiratory support. The support received were invasive in 16 $(32.7 \%)$ and non-invasive in33 (67.3\%) (Table 2).

nCPAP devices were utilised to provide non-invasive support. $24(72.7 \%)$ of the 33 babies and $9(27.3 \%)$ of the 33 cases had the patented and the locally improvised CPAP devices.

Table 3 presents, Duration and indication for support with the mode of support $14 / 49$ babies $(28.6 \%)$ received support for less than 24 hours.

\begin{tabular}{lccc}
\hline $\begin{array}{l}\text { Table 3: Duration and indication for support with the mode of } \\
\text { support } \\
\text { Duration / Indication }\end{array}$ & $\mathrm{N}(\%)$ & \multicolumn{2}{l}{ Mode of Support } \\
& & NIV & Invasive \\
\hline $\begin{array}{l}\text { Length of time } \\
\text { Duration }\end{array}$ & & & \\
$<24$ hrs & $14(28.6)$ & $10(71.4)$ & $4(28.6)$ \\
1-7days & $34(69.4)$ & $23(67.7)$ & $11(32.4)$ \\
$>7$ days & $1(2)$ & - & $1(100.0)$ \\
Indication & Total & & \\
Distress & $36(73.5)$ & $33(91.7)$ & $3(8.3)$ \\
Failure & $13(26.5)$ & - & $13(100)$ \\
Total & 49 & $33(67.5)$ & $16(32.7)$ \\
\hline
\end{tabular}

Table 4 presents Gestational maturity with indication and Mode of support received. 13/16 of the mechanically ventilated had endo- tracheal intubation. $33 / 49(67.4 \%)$ of the supported babies survived Overall mortality in the supported babies was18/49 $(36.7 \%)$. Mortality was significantly higher in babies who received IVRS $(11 / 16(68.75 \%)$ compared to those that received NIVRS 7/33 (21.2\%); $\left(\mathrm{X}^{2}=10.478 ; \mathrm{p}=\right.$ 0.001). Their diagnosis ranged from Neonatal Tetanus, ABE, HIE, to Sepsis and RDS. The commonest indication for this mode of support was respiratory failure. Of the 33 babies who received NIVRS: 9 improvised nCPAP and 24 patented nCPAP, a total of 7 died. 4/9 $(44.4 \%)$ had the improvised CPAP. $3 / 24(12.5 \%)$ had the patented nCPAP. $\left(\mathrm{X}^{2}=3.997 ; \mathrm{p}=0.068\right.$ fishers exact test) There was no significant difference in outcome between the two groups. Among the dead babies who 
had IVRS; 3 term babies had ABE, 2 term babies had HIE and 1 ELBW had severe BA, 5 other preterm babies who also had IVRS died.

The neonatal mortality during the study period was 123.3 per thousand live births and respiratory related mortality contributed $25.4 \%$ to this rate.

The overall mortality for the supported babies was $36.7 \%$ : survival for the supported respiratory disorders was 33/49(67.4\%) \%. Survival for the modes are: IVRS is $(21.1 \%)$; NIVRS $(78.8 \%)$. Survival for the patented nCPAP is $21 / 24(87.5 \%)$ while for improvised $5 / 9$ $(55.5 \%)$ (Very small numbers)

\begin{tabular}{|c|c|c|c|c|c|}
\hline $\begin{array}{l}\text { Table } \\
\text { support }\end{array}$ & $\mathrm{Ge}$ & & iith & $\mathrm{d}$ & 1 \\
\hline $\begin{array}{l}\text { Gesta- } \\
\text { tional } \\
\text { maturity }\end{array}$ & $\mathrm{N}(\%)$ & $\begin{array}{l}\text { Indicati } \\
\text { Distress }\end{array}$ & Failure & $\begin{array}{l}\text { Mode of } \\
\text { NIV }\end{array}$ & $\begin{array}{l}\text { Support } \\
\text { Invasive }\end{array}$ \\
\hline & & & & & \\
\hline ete & 38 & 31 & 7( & 7) & 6.3) \\
\hline tal & $49(100)$ & $36(73.5)$ & $13(26.5)$ & $33(67.3)$ & $16(32.7)$ \\
\hline
\end{tabular}

$X^{2}=5.711, p=0.017 \quad X^{2}=3.091, p=0.079$

\section{Discussion}

A low respiratory support rate of $8.5 \%$ has been observed in this survey. This is much lower than $43 \%$ observed by the Canadian neonatal network. ${ }^{20}$ This low support rate can be accounted for by the relatively new introduction of respiratory support service in our centre compared to what obtains in a developed country's neonatal health care system. Neonatal respiratory support is available only in a few centres in our sub-region. ${ }^{16}$

Seventy seven per cent of the supported babies were preterm and this emphasises the fact that preterm births account for a sizeable proportion of our neonatal morbidities and mortalities. ${ }^{4}$ Evidence from literature confirms that high mortality rates are associated with preterm birth rates as these are often associated with complications the most important of which include RDS. ${ }^{21}$ Despite this, the industrialised economies have succeeded in driving down their neonatal mortality rates with the introduction of various forms of care for these high risk new-borns. Such forms of care are embodied in the context of Neonatal intensive care and regionalisation of care. ${ }^{22-24}$

In this study, majority of these preterm babies required only non- invasive support which mode appeared to have favoured their outcome as fewer of the babies with non- invasive support died. It is possible that the early provision of the support which was more proactive had allowed for the early relief of work done for breathing in such babies before worsening of their situation. This is in tandem with current recommendations. ${ }^{24}$

Among the babies who received non-invasive support, a few were supported with the local bubble nCPAP innovation. Given the high demands for support we had to utilise our locally improvised CPAP device to meet the needs. This local innovation may appear crude in their present form, however, its use also contributed to survival of these babies as there was no significant difference in outcomes compared with the use of the patented device. The use of such local innovations as previously reported by Audu et al contributed to improved status of babies with respiratory distress. ${ }^{25}$

The introduction of NICU as well as ventilator care in the developed countries yielded a sharp decline in neonatal mortality rates. ${ }^{21}$ This emphasises the point that urgent attention needs to be given to improving quality and standards of neonatal care in developing economy as would be commensurate to available means. This would support the need for innovative approaches to meet these demands. Such would include the widespread use of the bubble nCPAP in most parts of Nigeria so as to reduce neonatal mortality accruing from respiratory related causes.

As has been shown by this survey, $67.3 \%$ of cases of supported babies needed non-invasive support and this was associated with a lower mortality relative to the group who received invasive support. Non-invasive support requires less sophistication and can be provided in the context of a special care Baby unit in developing countries. $15,26,27$

Eight percent of the 576 babies assessed required respiratory support; nearly $10 \%$ of the total, this actually makes the case for the availability of devices even at the lowest level of sophistication in resource limited settings. Given that these were predominantly preterm babies who had RDS, it makes the case for other additional measures like the use of antenatal corticosteroids and the use of surfactant in these group of babies to optimise the non-invasive support that can be utilised in its simplest form in most of our communities in Nigeria.

Sixty eight percent of babies who received invasive support died. This high mortality rate might have been due to the severity of the primary disease, it might also have been due to the low capacity of the health work force to cope with the high level technical support needed for mechanically ventilated babies in resource poor settings. The babies who were supported with the IVRS had ABE, HIE III and NT, all of which are causes that are largely preventable. These direct causes of the morbidities can be tackled by implementation of widespread preventive strategies on a large scale. These may influence a decline in neonatal mortality as these causes are also related to the major causes of neonatal mortality in Nigeria.

The spectrum of disorders requiring respiratory support in our setting are largely similar to the National causes of neonatal mortality and to a large extent similar to the global causes of Neonatal mortality. ${ }^{3,4}$ This implies that the causes can be positively influenced by improved standard and quality of New-born care in Nigeria. This requires not only measures to introduce less sophisticated technology devices but also measures must be taken to enhance the capacity and skills of the neonatal care health work force as this is highly relevant to introduction of high level technology. This can be attested to 
by the fact that invasive respiratory support carried a high mortality rate which might not be only related to their morbidities of such babies but also to the skills of the carers. ${ }^{21}$ Such high level skills and care is best provided in the context of a neonatal Intensive care.

We recognise the role of various interventions in the drastic reduction of neonatal mortalities. Such include: Clean and safe delivery in the prevention of neonatal sepsis; prompt identification and treatment of infection further efforts should identify other interventions that could contribute significantly to mortality reduction particularly in a setting where health seeking behaviour is suboptimal. Such reductions could be achieved if attention is given to prompt management of respiratory problems.

The study is limited by the short duration of the report and it only evaluated for outcome in relation to mortality. Such works would be better measure of quality of care if it examined long term survival, as intact survival and quality of life beyond survival are far more important particularly in such low resource setting as ours.

Such works in the future should actually evaluate introduced strategies for how readily replicable and sustainable they may be. The influence of capacity development of providers of Neonatal care to outcomes should also be evaluated.

\section{Conclusion}

We examined the spectrum of conditions requiring respiratory support they are disorders that lead to respiratory distress and respiratory failure. These predominantly required management with non-invasive techniques of the nCPAP. Respiratory support contributed to survival in these babies. There is thus urgent need to make available in Nigeria institutions that provide neonatal care, basic non-invasive respiratory support as a possible cost effective intervention for neonatal mortality reduction.

\section{Conflict of interest: None \\ Funding: None}

\section{Acknowledgements}

The Authors gratefully acknowledge the superlative care provided by the nurses on the Neonatal Unit and the contribution of the Resident doctors in the care of these Babies

\section{Reference}

1. Okolo AA, Okonkwo IR, Ideh RC. Challenges and opportunities for neonatal respiratory support in Nigeria: a case for regionalization of care. Niger J Paed 2016; 43 (2):

2. Lee KS, Paneth N, Gartner LM,Pearlman MA, Gruss L. Neonatalmortality: an analysis of the recentimprovement in the United States. Am J Public Health. 1980;70:15-21.

3. Peter de Winter J, Machteld A, de Vries G, et al. Clinical practice Noninvasive respiratory support in newborns. Eur J Pediatr 2010; 169:777-782

4. Saving newborn lives in Nigeria: Newborn health in the context of the Integrated Maternal, Newborn and Child Health Strategy. Abuja: Federal Ministry of Health, Save the Children, ACCESS; 2009. www.savethechildren.org/ savenewborns.

5. Committing to Child Survival: A Promise Renewed. Progress report 2014 UNICEF.

6. Clifford S. The problem of prematurity: obstetric, pediatric, and socioeconomic factors. J Pediatr. 1955;47 (1):13-24.

7. Mathews T, MacDorman M. Infant mortality statisticsfromthe2006periodlinked birth/infant death data set. Natl Vital Stat Rep. 2010;58 (17): 1-31.
8. Lussky R. A century of neonatal medicine. Minn Med. 1999;82 (12):48-54.

9. Lawn JE, Kerber K, EnweronuLaryea C, Massee Bateman O. New born survival in low resource settings: are we delivering? BJOG. 2009;116(suppl 1):49-59.

10. Philip A. Chronic lung disease of prematurity: a short history. Semin Fetal Neonatal Med. 2009;14 (6):333-338

11. Swyer PR. An assessment of artificial respiration in the newborn. In: Problems of Neonatal Intensive Care Units: Report of the 59th Ross Conference on Pediatric Research. Columbus, OH: Ross Laboratories; 1969:25-35.

12. Kumar P, Sandesh Kiran PS. Changing trends in the management of respiratory distress syndrome (RDS). Indian J Pediatr. 2004;71:49-54.

13. Bhakoo O, Narang A, Ghosh K. Assisted ventilation in neonates: an experience with 120 cases. Presented at: IX Annual Convention of National Neonatology Forum; Manipal, India; February 17-20.

14. Garg P, Krishak R, Shukla D. NICU in a community level hospital. Indian J Pediatr.2005; 72:2730.
15. Bhutta Z, Yusuf K. Profile and outcome of the respiratory distress syndrome among newborns in Karachi: risk factors for mortality. J Trop Pediatr. 1997;43 (3):143-148.

16. Okonkwo IR, Abhulimhen-Iyoha BI, Okolo AA. Scope of neonatal care services in major Nigerian hospitals. Niger J Paed 2016; 43 (1):8-13.

17. Northway WH Jr, Rosan RC, Porter DY. Pulmonary disease following respiratory therapy of hyaline membrane disease. Bronchopulmonary dysplasia. $N$ Engl J Med. 1967; 276:357-368.

18. Lawn JE, Kerber K, EnweronuLaryea C, Cousens S. 3.6 Million Neonatal Deaths-What Is Progressing and What Is Not? Seminars in Perinatology 2010; 34 : 371-386.

19. Silverman WC, Anderson DH. Controlled clinical trial on effects of water mist on obstructive respiratory signs, death rate and necropsy findings among premature infants. Pediatrics 1956; 17 : $1-4$.

20. Lee SK, McMillan D, Ohlsson A, et al. Canadian Neonatal Network: Variations in practice and outcomes of the Canadian NICU Network: 1996-7. Pediatrics 2000, 106:1070-9. 
21. Kamath BD, MacGuire ER, McClure EM, Goldenberg RL, Jobe AH (2011) Neonatal Mortality from Respiratory Distress Syndrome: Lessons for Low Resource Countries. Pediatrics 127: 11391146.

22. American Academy of Pediatrics, Committee on Fetus and Newborn. Levels of neonatal care. Pediatrics. 2012;130 (3):587-597. doi:10.1542/peds.2012-1999.

23. Lee KS, Paneth N, Gartner LM, Pearlman MA, Gruss L. Neonatal mortality: an analysis of the recent improvement in the United States. Am J Public Health. 1980;70:1521.
24. Committee on fetus and newborn, American Academy of Paediatrics Respiratory support in preterm infants at birth. Pediatrics 2014; 133:171.

25. Audu LI, Otuneye AT, Mukhtar MY, et al. Customized bubble continuous airway pressure device at the National Hospital Abuja for the treatment of respiratory distresss syndrome (RDS). Niger J Paediatr 2013: 40: 275-277.
26. Chen A, Deshmukh AA, Richards -Kortum R, Molyneux E, Kawaza $\mathrm{K}$, Cantor SB.Cost-effectiveness analysis of a low-cost bubble CPAP device in providing ventilatory support for neonates in Malawi - a preliminary report BMC Pediatrics 2014, 14: 288.

27. Rezzonico R, Caccamo LM, Manfredini V, Cartabia M, et al. Impact of the systematic introduction of low- cost bubble Nasal CPAP in a NICU of a developing country: a prospective pre-and post-intervention study. $B M C$ Pediatrics (2015) 15:26. 